\title{
Comparison of biochemical parameters among DPP4 inhibitor users and other oral hypoglycaemic drug users: a cross-sectional study from Anuradhapura, Sri Lanka
}

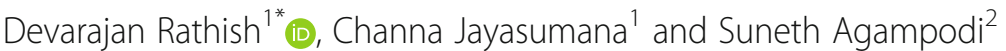

\begin{abstract}
Background: Higher efficacy of incretin-based therapies for type 2 diabetes mellitus has been reported from Asia. Pancreatitis and hepatitis have also been suspected to occur due to dipeptidyl peptidase-4 inhibitor (DPP4l) treatment. The present study aims at comparing selected biochemical parameters among DPP4 inhibitor users and other oral hypoglycaemic drug users.

Methods: Patients were recruited from the State Pharmaceutical Corporation, Anuradhapura, Sri Lanka, for a comparative cross-sectional study. Two groups were involved: "DPP4l" user group $(n=63)$ and "other oral hypoglycaemic" user group $(n=126)$. Mann-Whitney $U$ test was performed to find a significant difference $(p<0.05)$ in the distributions of $\mathrm{HbA}_{1 c}$, pancreatic amylase, serum lipase, AST and ALT levels between the two groups.

Results: Contradicting to previous Asian studies, distribution of $\operatorname{HbA}_{1 C}(p=0.569)$ between anti-diabetic regimes with and without DPP4 inhibitors showed no significant difference. Also, amylase $(p=0.171)$, AST $(p=0.238)$ and ALT ( $p=0.347)$ failed to show significance. However, lipase was significantly $(p=0.012)$ high in the DPP4I group.

Conclusion: The study showed a significantly higher lipase level among the DPP4I users in comparison to other oral hypoglycaemic drug users, and possible reasons were discussed.
\end{abstract}

Keywords: Diabetes mellitus, HbA 1 c, Amylase, Lipase, AST, ALT, Pancreatitis, Hepatitis, Safety, Efficacy

\section{Background}

The diabetes atlas of the international diabetes federation reveals $8.8 \%, 8.5 \%$ and $8.6 \%$ as the prevalence of diabetes (ages 20-79) for the globe, Southeast Asia and Sri Lanka respectively [1]. An increase in type 2 diabetes mellitus (T2DM) along with the use of pesticides has been observed in Southeast Asia [2]. Organophosphate-induced disruption of glucose homoeostasis [3, 4] along with an attenuation of the "incretin effect" $[5,6]$ has been proposed among Asians. Furthermore, higher efficacy of incretin enhancers has been reported among Asians for T2DM [7, 8].

Along with the dysfunction of pancreatic beta cells and insulin resistance [9], patients with T2DM have

\footnotetext{
*Correspondence: rathishdeva@gmail.com

'Department of Pharmacology, Faculty of Medicine and Allied Sciences,

Rajarata University of Sri Lanka, Saliyapura, Sri Lanka

Full list of author information is available at the end of the article
}

shown attenuation of the incretin effect $[10,11]$. There is an additional $40-60 \%$ of insulin secretion with oral glucose in comparison to the same dose of intravenous glucose; this is known as the 'incretin effect' [12, 13]. Glucagon-like peptide-1 (GLP-1) is one of the two most essential incretin hormones [14, 15]. These hormones increase insulin and thereby reduce blood glucose levels. Also, incretin hormones delay gastric emptying and suppress appetite. Dipeptidyl peptidase-4 (DPP4) enzyme metabolises these gut hormones [14, 15]. DPP4 inhibitors (DPP4I) are orally administered medicines which reduce the inactivation of incretin hormones and prolong their activity by inhibiting the enzyme DPP4 [16]. Thereby, they increase insulin secretion in response to meals. Sitagliptin, vildagliptin, saxagliptin, linagliptin and alogliptin belong to the DPP4I group [16-18].

(c) The Author(s). 2019 Open Access This article is distributed under the terms of the Creative Commons Attribution 4.0 International License (http://creativecommons.org/licenses/by/4.0/), which permits unrestricted use, distribution, and reproduction in any medium, provided you give appropriate credit to the original author(s) and the source, provide a link to the Creative Commons license, and indicate if changes were made. The Creative Commons Public Domain Dedication waiver (http://creativecommons.org/publicdomain/zero/1.0/) applies to the data made available in this article, unless otherwise stated. 
Consideration of adverse effects is essential when choosing an anti-diabetic regime. Reports of acute pancreatitis (fatal and non-fatal) were available for sitagliptin, a commonly used DPP4I $[16,18]$. Meta-analyses reveal no increased risk of pancreatitis with DPP4Is [19, 20]. However, most of these reviews conclude with the need for future observational studies to establish an association. T2DM itself is known to cause elevated levels of serum pancreatic-specific amylase and serum lipase [21]. Also, a pattern of increase in unknown effects may be observed when a new agent is introduced to the market, and its use becomes more widespread [22]. However, elevated serum amylase or lipase levels with DPP4Is are still a concern [23]. Also, rare risk of hepatitis has been noted with vildagliptin [18]. Immediate discontinuation is advised if the above two serious adverse effects occur [18].

The study aims to find a significant difference in efficacy using levels of $\mathrm{HbA}_{1 \mathrm{C}}$, among patients of Anuradhapura, Sri Lanka, who were on oral anti-diabetic regimes with and without DPP4Is; pancreatic amylase and lipase were used to compare the risk of pancreatitis; aspartate aminotransferase (AST) and alanine aminotransferase (ALT) were used to compare the risk of hepatitis. Our null hypothesis is that "there is no significant difference in the levels of $\mathrm{HbA}_{1 \mathrm{C}}$, pancreatic amylase, lipase, AST and ALT among T2DM patients of Anuradhapura who were on oral anti-diabetic regimes with and without DPP4Is".

\section{Methods}

\section{Study setting}

This comparative cross-sectional study was conducted at the State Pharmaceutical Corporation (SPC), Anuradhapura during April-June 2017. Anuradhapura is the largest district of North-central province and in Sri Lanka by surface area. In 2012, it had a population of nearly 856,500 [24]. The majority (94.6\%) belongs to the rural sector [24]. Agriculture is their primary (46\%) employment [25]. Anuradhapura is also known for the use and abuse of pesticides like organophosphate [26, 27] which are implicated with T2DM [3, 4].

SPC promotes generic prescribing and sells drugs at affordable prices compared to private pharmacies [28]. The prices of $100 \mathrm{mg}$ and $50 \mathrm{mg}$ sitagliptin tablets at the SPC were Sri Lankan rupees 36 (USD 0.23) and 15 (USD 0.10) respectively during the study period. However, private pharmacies sold the above two at Sri Lankan rupees 74 (USD 0.48) and 46 (USD 0.30) respectively. The only outlet of SPC in Anuradhapura is situated very close to the Teaching Hospital Anuradhapura. Also, private diabetic clinics are within $500 \mathrm{~m}$ from the SPC, Anuradhapura. The next outlet of SPC is either in the districts of Polonnaruwa, Kurunegala or Jaffna districts which are 100, 115 and $200 \mathrm{~km}$ away respectively. The Teaching Hospital provides universal-free health care and is the only tertiary care hospital available for the entire North-central Province, which is maintained by the government. The above facts make Teaching Hospital, the only low-cost option for T2DM patients of Anuradhapura to seek specialised care. Although government hospitals in Anuradhapura have shown high availability of anti-diabetic agents [29], DPP4Is are not available in state-owned hospitals of Sri Lanka. Due to the above reasons, a large number of low-middle-income population visits SPC to obtain anti-diabetic drugs including DPP4Is. Oral hypoglycaemic agents were found to be within the top ten dispensed drugs at SPC [30].

\section{Sampling method}

According to the standards of medical care in diabetes2018 by the American diabetes association, metformin is recommended as monotherapy in type 2 diabetes mellitus unless contra-indicated [31]. Therefore, DPP4Is are rarely used as monotherapy at the local setting. Two groups were chosen for comparison. Those receiving DPP4Is (sitagliptin, linagliptin, saxagliptin, vildagliptin or alogliptin) as part of a dual or triple-drug regime were recruited to the "DPP4I group". Those who have never received DPP4Is and were on any other dual or triple oral anti-diabetic regime were recruited to the "other oral hypoglycaemic $(\mathrm{OOH})$ group". All consecutive eligible patients presented to SPC were sampled for the $\mathrm{OOH}$ group until the minimum sample size was achieved. The $\mathrm{OOH}$ group produced a male to female ratio of 4:3. Then, patients were recruited for the DPP4I group to achieve the same male to female ratio by separately sampling all consecutive males and females who were eligible for the DPP4I group until the minimum sample size was achieved for each gender (DPP4I group male $=36$; female $=27$ ). Age and duration of diabetes mellitus were checked for a significant difference between the two groups by using the Mann-Whitney $U$ test.

\section{Selection criteria}

Inclusion criteria were the following: aged 18 to 70 years, permanent residence at Anuradhapura for $\geq 5$ years, type 2 diabetes mellitus for $\leq 20$ years, dual or triple oral anti-diabetic therapy for the last 3 months and not having chronic kidney disease as measured by eGFR of $\geq 60 \mathrm{ml} /$ $\min / 1.73 \mathrm{~m}^{2}$ according to the CKD-EPI equation. Exclusion criteria were the following: any acute illness, history of parenteral anti-diabetic therapy, Morisky-Green-Levine test medical adherence score of 0-1 [32], history of chronic gastrointestinal disorders, pancreatic disorders, liver disease or malignancy, history of immunosuppression (steroid treatment or chemotherapy), everyday smokers [33], heavy alcohol users [34] and pregnancy. 


\section{Sampling size}

Minimum sample sizes were calculated as 63 and 126 (1:2), for "DPP4I group" and "other oral hypoglycaemic $(\mathrm{OOH})$ group" respectively using data from previous literature [35] and the formula: $n_{\mathrm{B}}=(1+1 / k)\left[\sigma \times\left(Z_{1-\alpha / 2}+Z_{1-\beta}\right) /\left(\mu_{\mathrm{A}}\right.\right.$ - $\left.\left.\mu_{\mathrm{B}}\right)\right]^{2}$. Where, $n_{\mathrm{B}}$ is the calculated sample size for the DPP4I group (=63), $k$ is $n_{\mathrm{A}} / n_{\mathrm{B}}$ (matching ratio) (=02), $\sigma$ is the standard deviation $(=2.3), Z_{1-\alpha / 2}$ is the type I error $(=1.96), Z_{1-\beta}$ is the power $(=0.8), \mu_{\mathrm{A}}$ is the $\mathrm{OOH}$ group mean $(=7.4)$ and $\mu_{\mathrm{B}}$ is the DPP4I group mean (=8.4).

\section{Instruments and investigations}

Demographic data, details on co-morbidities, anthropometric measurements, blood pressure measurement and blood samples for serum creatinine, $\mathrm{HbA}_{1 \mathrm{C}}$, serum pancreatic-specific amylase, serum lipase, AST and ALT were obtained. Study description, obtaining written informed consent, data collection and physical examination were done by the first author in a separate room at SPC, Anuradhapura. All necessary measures were taken to preserve participant's privacy and confidentiality.

Blood samples for the relevant investigations were analysed at the Durdans Hospital Laboratory, Anuradhapura. It is a Joint Commission International accredited hospital in Sri Lanka. Procedures for measurement of the above investigations were well established and routinely done at the above laboratory. The methods used for the analysis of serum creatinine, $\mathrm{HbA}_{1 \mathrm{C}}$ levels, pancreatic specific amylase, lipase, AST and ALT were enzymatic colorimetric assay, high-performance liquid chromatography, enzymatic colorimetric assay, enzymatic colorimetric assay, photometric rate (L-aspartate with 2-oxoglutarate) and photometric rate (L-alanine with 2-oxoglutarate) respectively. Quality control for $\mathrm{HbA}_{1 \mathrm{C}}$ was maintained using Bio-Rad lyphochek low and high control [36] and for amylase, lipase, AST and ALT using ROCHE Precinorm U and Precipath U [37].

\section{Data analysis and description}

Data was entered to a Microsoft Excel sheet (Additional file 1). Descriptive statistics were used to describe data. Median (interquartile range) and mean (SD) were presented for the biochemical parameters focused in this study. As data were not normally distributed, Mann-Whitney $U$ test was performed to determine differences between the distribution of $\mathrm{HbA}_{1 \mathrm{C}}$, amylase, lipase, AST, ALT, BMI, waist circumference and blood pressure of the two groups $(p<0.05)$. Additional analysis was done using the chi-square test (and Fisher exact where appropriate) to determine significant differences between the proportions having co-morbidities $(p<0.05)$.

\section{Results}

Most were Buddhist $(\mathrm{OOH}=98 \%$, DPP4I $=92 \%)$ from Nuwaragam Palata East divisional secretariat division $(\mathrm{OOH}=43 \%, \mathrm{DPP} 4 \mathrm{I}=51 \%)$ and educated up to or above the general certificate of education (advanced level) $(\mathrm{OOH}$ $=45 \%$, DPP4I $=52 \%)$ among participants of both groups. Most (48\%) were either unemployed or retired among patients of both the groups. The demographic data, co-mo rbidities, anthropometric data and blood pressure measurement for both the groups are compared in Table 1. The distribution of BMI $(p=0.008)$ and waist circumference ( $p$ $=0.001)$ for the DPP4I group were significantly different from that of the $\mathrm{OOH}$ group. Proportion having dyslipidaemia $(p=0.017)$ and hypertension $(p=0.040)$ was significantly high in the DPP4I group. The top five drugs used for other co-morbidities in the two groups are shown in Fig. 1.

A higher median of $\mathrm{HbA}_{1 \mathrm{C}}[8.5 \%(69 \mathrm{mmol} / \mathrm{mol})]$ was found among DPP4I users, compared to that of the $\mathrm{OOH}$ group [8.4\% $(68 \mathrm{mmol} / \mathrm{mol})]$. However, there was no significant difference in the distribution of $\mathrm{HbA}_{1 \mathrm{C}}$ between the two groups $(p=0.569) .19 .1 \%(24 / 126)$ of $\mathrm{OOH}$ group had $\mathrm{HbA} 1 \mathrm{c}$ values of $<7 \%(<53 \mathrm{mmol} / \mathrm{mol})$, whereas it was $22.2 \%(14 / 63)$ in the DPP4I group (chi-square statistic $=0.264, p=0.608)$. A significant difference was observed between the distributions of serum lipase of the two groups $(p=0.012)$. A higher median of serum lipase (52 U/L) was found in the DPP4I group compared to that of the $\mathrm{OOH}$ group $(45 \mathrm{U} / \mathrm{L})$. However, pancreatic amylase, AST and ALT failed to show a significant difference (Table 2). Further analysis among non-dyslipidaemic patients $(n=107)$ revealed median serum lipase values of 45 $\mathrm{U} / \mathrm{L}$ and $47.5 \mathrm{U} / \mathrm{L}$ for $\mathrm{OOH}(n=79)$ and DPP4I $(n=28)$ groups respectively. The distribution of the above serum lipase levels failed to show a significant difference between the two groups $(p=0.246)$.

Additional analysis was done for dual and triple regimes separately. 97.6\% (123/126) and 11.1\% (07/63) were on dual regimes for $\mathrm{OOH}$ and DPP4I groups respectively. $\mathrm{HbA}_{1 \mathrm{C}}$ for dual regimes of DPP4I users [7.5\% $(58 \mathrm{mmol} / \mathrm{mol})]$ was lower in its median but was not significantly different in distribution compared to the $\mathrm{OOH}$ users $[8.4 \%(68 \mathrm{mmol} / \mathrm{mol})](p=0.110)$. Lipase for dual regimes of DPP4I users was higher in its median $(60 \mathrm{U} / \mathrm{L}$ vs $45 \mathrm{U} / \mathrm{L}$ ) and was significantly different in distribution compared to the $\mathrm{OOH}$ users $(p=0.007)$. However, pancreatic amylase, AST and ALT failed to show a significant difference (Table 3).

$\mathrm{OOH}$ and DPP4I groups had 2.4\% (3/126) and 88.9\% $(56 / 63)$ patients respectively on the triple regime. The overall median $\mathrm{HbA}_{1 \mathrm{C}}$ for the triple regime of $\mathrm{OOH}$ group $[7.8 \%(62 \mathrm{mmol} / \mathrm{mol})]$ was lower compared to that of the DPP4I group $[8.5 \%(69 \mathrm{mmol} / \mathrm{mol})]$. The median of serum lipase for the triple regime of DPP4I group (51 
Table 1 Characteristics of the study participants_DPP4I study, Anuradhapura 2017

\begin{tabular}{|c|c|c|c|}
\hline Items & $\mathrm{OOH}$ group $(n=126)$ & DPP4I group $(n=63)$ & $p$ value \\
\hline \multicolumn{4}{|l|}{ Demography } \\
\hline Median age and IQR (years) & $53.5(47-59)$ & $54(48-60)$ & $0.968^{*}$ \\
\hline Median duration of T2DM and IQR (months) & $66(24-120)$ & $72(36-120)$ & $0.204^{*}$ \\
\hline \multicolumn{4}{|l|}{ Co-morbidities } \\
\hline Dyslipidaemia & $37.3 \%(47 / 126)$ & $55.6 \%(35 / 63)$ & $0.017 \wedge$ \\
\hline Hypertension & $44.4 \%(56 / 126)$ & $60.3 \%(38 / 63)$ & $0.040^{\wedge}$ \\
\hline Ischaemic heart disease & $9.5 \%(12 / 126)$ & $12.7 \%(8 / 63)$ & $0.504 \wedge$ \\
\hline Hypothyroidism & $3.2 \%(4 / 126)$ & $1.6 \%(1 / 63)$ & $0.086^{\#}$ \\
\hline Hyperthyroidism & $1.6 \%(2 / 126)$ & $3.2 \%(2 / 63)$ & $0.815^{\#}$ \\
\hline Asthma & $1.6 \%(2 / 126)$ & 00 & $0.887^{\#}$ \\
\hline Osteoarthritis & $0.8 \%(1 / 126)$ & 00 & $0.999^{\#}$ \\
\hline \multicolumn{4}{|l|}{ Anthropometric measurements and blood pressure } \\
\hline Median BMI and IQR $\left(\mathrm{kgm}^{-2}\right)$ & $25.3(23-28)$ & $26.8(24-30)$ & $0.008^{*}$ \\
\hline Median waist circumference and IQR (cm) & $92.5(88-99)$ & $97(92-102)$ & $0.001^{*}$ \\
\hline Median systolic blood pressure and IQR (mmHg) & $138.5(125-156)$ & $141(129-151)$ & $0.749^{*}$ \\
\hline Median diastolic blood pressure and IQR $(\mathrm{mmHg})$ & $84(76-90)$ & $84(79-90)$ & $0.542^{*}$ \\
\hline
\end{tabular}

$B M I$ body mass index, DPP4I dipeptidyl peptidase 4 inhibitors, IQR interquartile range, $\mathrm{OOH}$ other oral hypoglycaemics, T2DM type 2 diabetes mellitus *Mann-Whitney $U$ test was performed

${ }^{\wedge}$ Chi-square test was performed

"Fisher exact was performed

$\mathrm{U} / \mathrm{L})$ was higher compared to that of the $\mathrm{OOH}$ group (45 U/L) (Table 4). As the OOH group had only 03 patients, a statistical test was not performed to find a significant difference in distribution.

Metformin-tolbutamide combination recorded the lowest mean for $\mathrm{HbA}_{1 \mathrm{C}}$ [8.1\% (SD 2.8)] among the dual therapies of the $\mathrm{OOH}$ group. All dual therapies in the DPP4I group had lower mean $\mathrm{HbA}_{1 \mathrm{C}}$ values than the $\mathrm{OOH}$ group; the lowest was seen with sitagliptin-glimepiride combination (6.2\%, $n=01)$. Metformin SR-tolbutamide-pioglitazone combination recorded the lowest mean for $\mathrm{HbA}_{1 \mathrm{C}}(6.8 \%, n$ $=01$ ) among the triple therapies of the $\mathrm{OOH}$ group; it was sitagliptin-metformin SR-glimepiride combination [ $[7.6 \%$ (SD 1.1)] in the DPP4I group. Sitagliptin-metformin combination recorded the highest mean for serum lipase among dual therapies of the DPP4I group. It was

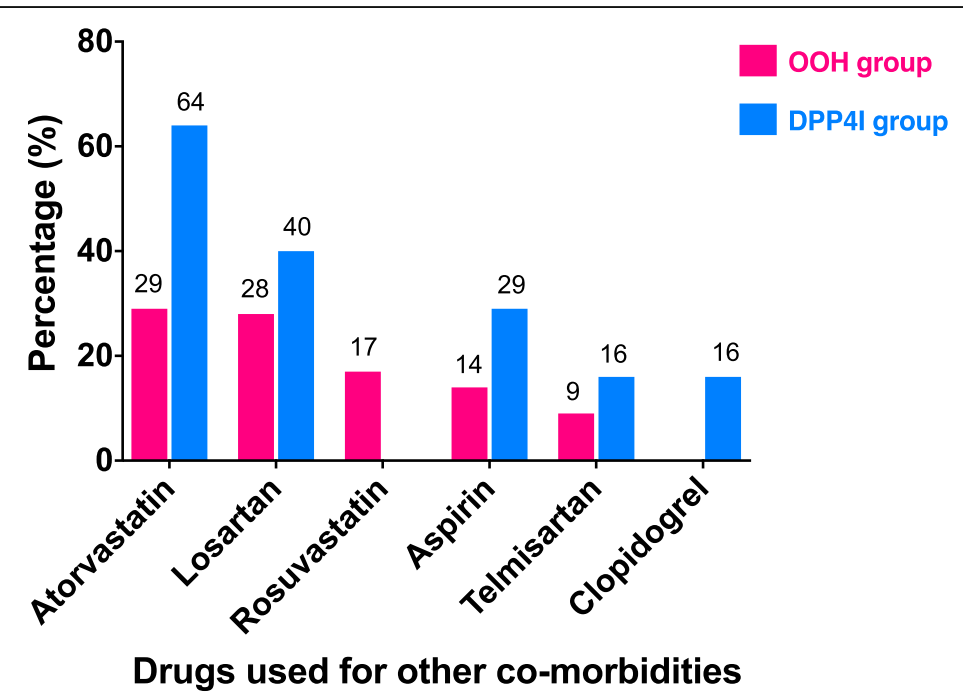

$\mathrm{OOH}$ - Other oral hypoglycaemics, DPP4I - Dipeptidyl peptidase 4 inhibitors

Fig. 1 Top five drugs used by diabetic patients for other co-morbidities of the two groups, DPP4I study, Anuradhapura 2017 
Table 2 Biochemical parameters for all types of therapies_DPP4I study, Anuradhapura 2017

\begin{tabular}{|c|c|c|c|c|c|c|}
\hline \multirow[t]{2}{*}{ Investigation } & \multicolumn{2}{|c|}{$\mathrm{OOH}$ group $(n=126)$} & \multicolumn{2}{|c|}{ DPP4I group $(n=63)$} & \multirow[t]{2}{*}{ Estimated difference of means ( $95 \% \mathrm{Cl})$} & \multirow[t]{2}{*}{$p$ value* } \\
\hline & Median (IQR) & Mean (SD) & Median (IQR) & Mean (SD) & & \\
\hline eGFR $\left(\mathrm{ml} / \mathrm{min} / 1.73 \mathrm{~m}^{2}\right)$ & $88.5(73-101)$ & $88.2(17.0)$ & $88(71-98)$ & $85.9(16.4)$ & $-2.3(-7.4$ to 2.8$)$ & 0.379 \\
\hline $\mathrm{HbA}_{1 \mathrm{C}}(\%)$ & $8.4(7-10)$ & $8.8(1.9)$ & $8.5(7-10)$ & $8.6(1.8)$ & $-2.0(-0.8$ to 0.4$)$ & 0.569 \\
\hline Pancreatic amylase (U/L) & $36(27-48)$ & $44.8(57.1)$ & $38(32-55)$ & $47(27.1)$ & $2.2(-12.8$ to 17.2$)$ & 0.171 \\
\hline Serum lipase (U/L) & $45(35-60)$ & $48.6(18.6)$ & $52(42-73)$ & $69.9(67.2)$ & 21.3 (8.6 to 34.0 ) & 0.012 \\
\hline AST (U/L) & $23(17-30)$ & $26.4(18.4)$ & $25(20-32)$ & $28.3(15.9)$ & $1.9(-3.5$ to 7.3$)$ & 0.238 \\
\hline ALT (U/L) & $22(15-33)$ & $26(15.5)$ & $24(16-34)$ & 29.9 (19.9) & $3.9(-1.3$ to 9.1$)$ & 0.347 \\
\hline
\end{tabular}

$\mathrm{Cl}$ confidence interval, DPP4I dipeptidyl peptidase 4 inhibitors, IQR interquartile range, $\mathrm{OOH}$ other oral hypoglycaemics

*Mann-Whitney $U$ test was performed

sitagliptin-metformin-gliclazide MR combination among triple therapies of the DPP4I group. Tables 5 and 6 summarise the mean (SD) for biochemical parameters among dual and triple therapies respectively.

\section{Discussion}

In contrast to previous literature $[7,8,35,38]$, this study failed to show a significantly lower $\mathrm{HbA}_{1 \mathrm{C}}$ with DPP4I regimes. Also, it showed a significantly higher level of lipase as against previous meta-analyses [19, 20]. T2DM patients from Anuradhapura are not benefited by DPP4Is as much as other Asians. Aetio-pathology, meal pattern, socio-cultural and pharmaco-genomic differences would have contributed. DPP4I inhibits the degradation of already secreted GLP-1. Hence, if widespread use or abuse of organophosphate [26, 27] had attenuated GLP-1 secretion [5, 6] among dwellers of Anuradhapura, DPP4Is would be less effective. However, further experiments are essential to find a definitive causality.

There were no previous similar Sri Lankan data, so data from other neighbouring Southeast Asian countries were used to compare the study findings. A Malaysian study showed a significantly low $(P<0.001) \mathrm{HbA}_{1 \mathrm{C}}$ for DPP4I users compared to that of controls (7.4\% vs $8.4 \%)$ [35]. Better glucose indices with the sitagliptin-metformin combination in comparison to the glimepiride-metformin combination were seen among South Koreans [38]. Lando et al. have shown that $36 \%$ of incretin modulator drug users had an increase in levels of serum amylase or lipase (or both) compared to $18 \%$ of the controls [23]. In Taiwan, a significantly higher risk of acute pancreatitis, within the first 2 years of the initiation of sitagliptin, was found [39]. However, two other Taiwan studies have shown no significance [40, 41]. Also, a national survey in Denmark, systematic reviews and meta-analysis have provided evidence against an increased risk of pancreatitis with the use of incretin modulators [19, 20, 42, 43].

The distributions of BMI and waist circumference in the DPP4I group were significantly higher compared to that of the $\mathrm{OOH}$ group. Significantly higher proportions of participants with dyslipidaemia and hypertension were seen among the DPP4I users. DPP4Is are weight neutral [16], attenuate the risk of cardiovascular disease [44] and show a significant reduction in cholesterol, low-density lipoprotein [45] and blood pressure [45]. Therefore, the present findings related to BMI, waist circumference, dyslipidaemia and hypertension might be due to the preference of DPP4Is by physicians for T2DM patients who had the above co-morbidities. However, pancreatitis secondary to dyslipidaemia is well reported [46-49]. 'Dyslipidaemia induced pancreatitis' most commonly present with a poorly controlled diabetes and a history of hypertriglyceridemia [47]. Another study revealed that patients with pancreatitis secondary to dyslipidaemia are predominantly obese and diabetic [48]. Therefore, dyslipidaemia could have contributed to the observed higher median of serum lipase among

Table 3 Biochemical parameters for dual therapies_DPP4I study, Anuradhapura 2017

\begin{tabular}{|c|c|c|c|c|c|c|}
\hline \multirow[t]{2}{*}{ Investigation } & \multicolumn{2}{|c|}{$\mathrm{OOH}$ group $(n=123)$} & \multicolumn{2}{|c|}{ DPP4I group $(n=07)$} & \multirow[t]{2}{*}{ Estimated difference of means ( $95 \% \mathrm{Cl}$ ) } & \multirow[t]{2}{*}{$p$ value $^{*}$} \\
\hline & Median (IQR) & Mean (SD) & Median (IQR) & Mean (SD) & & \\
\hline $\mathrm{HbA}_{1 \mathrm{c}}(\%)$ & $8.4(7-10)$ & $8.8(1.9)$ & $7.5(7-8)$ & $7.7(1.2)$ & $-1.1(-2.5$ to 0.3$)$ & 0.110 \\
\hline Pancreatic amylase (U/L) & $36(27-48)$ & $44.3(57.6)$ & $58(32-97)$ & $60.1(33.1)$ & $15.8(-27.8$ to 59.4$)$ & 0.095 \\
\hline Serum lipase (U/L) & $45(35-60)$ & $48.7(18.8)$ & $60(52-148)$ & $91.6(48.1)$ & $42.9(26.7$ to 59.1$)$ & 0.007 \\
\hline AST (U/L) & $23(17-29)$ & $26.2(18.5)$ & $23(22-28)$ & $24.1(7.2)$ & $-2.1(-16.0$ to 11.8$)$ & 0.912 \\
\hline $\operatorname{ALT}(U / L)$ & $22(15-33)$ & $26.1(15.5)$ & $24(18-29)$ & $23.4(7.6)$ & $-2.7(-14.4$ to 9.0$)$ & 0.992 \\
\hline
\end{tabular}

$\mathrm{Cl}$ confidence interval, DPP4I dipeptidyl peptidase 4 inhibitors, IQR interquartile range, $\mathrm{OOH}$ other oral hypoglycaemics

*Mann-Whitney $U$ test was performed 
Table 4 Biochemical parameters for triple therapies_DPP4I study, Anuradhapura 2017

\begin{tabular}{|c|c|c|c|c|c|}
\hline \multirow[t]{2}{*}{ Investigation } & \multicolumn{2}{|c|}{$\mathrm{OOH}$ group $(n=03)$} & \multicolumn{2}{|c|}{ DPP4I group $(n=56)$} & \multirow[t]{2}{*}{ Estimated difference of means $(95 \% \mathrm{Cl}$} \\
\hline & Median (IQR) & Mean (SD) & Median (IQR) & Mean (SD) & \\
\hline $\mathrm{HbA}_{1 \mathrm{c}}(\%)$ & $7.8(7-8)$ & $7.5(0.6)$ & $8.5(7-10)$ & $8.7(1.8)$ & $1.2(-0.9$ to 3.3$)$ \\
\hline Pancreatic amylase (U/L) & $80(41-80)$ & $67(22.5)$ & $36.5(31-52)$ & $45.3(26.2)$ & $-21.7(-52.6$ to 9.3$)$ \\
\hline Serum lipase (U/L) & $45(41-46)$ & $44(2.7)$ & $51(40-71)$ & $67.2(69.1)$ & $23.2(-57.4$ to 103.8$)$ \\
\hline AST (U/L) & $27(14-55)$ & $32(21)$ & $26(19-34)$ & $28.9(16.6)$ & $-3.1(-23.0$ to 16.8$)$ \\
\hline $\operatorname{ALT}(U / L)$ & $16(12-43)$ & $23.7(16.9)$ & $24(16-37)$ & $30.8(20.8)$ & $7.1(-17.4$ to 31.6$)$ \\
\hline
\end{tabular}

As $\mathrm{OOH}$ group has only 03 , a statistical test was not performed to find a significant difference in distribution

$\mathrm{Cl}$ confidence interval, DPP4I dipeptidyl peptidase 4 inhibitors, IQR interquartile range, $\mathrm{OOH}$ other oral hypoglycaemics

the DPP4I users compared to that of the OOH users. As this is a cross-sectional study, the above observation could be an example of 'confounding by indication'. An exposure (DPP4I) looks as if associated with an outcome (pancreatitis). However, the outcome (pancreatitis) could be resulted due to an indication (dyslipidaemia) for which the exposure (DPP4I) was used [50]. Also, additional analysis among non-dyslipidaemic patients revealed no significant difference between the two groups $(p=0.246)$ in relation to the distribution of the serum lipase levels.

Glycaemic control could have been confounded by differences between the two groups in age, duration of diabetes mellitus, sex, level of adherence to treatment regime and number of anti-diabetic agents used. However, there was no significant difference in the distribution of age $(p=0.968)$ and duration of diabetes mellitus $(p=0.204)$ between the two groups. Both groups were sex matched. Only the patients with a Morisky-Green-Levine test medical adherence score of 2-4 (moderate to high) were included. Both groups had only patients who were on either dual or triple oral anti-diabetic therapy, and separate analysis on dual and triple therapies had similar findings to the overall results.

This study measured AST and ALT as these are commonly used in screening of hepatitis and are considered excellent markers of hepatocellular injury [51]. Diagnosis of hepatitis could be made using biochemical and radiological investigations. Future similar studies, using a combination of biochemical and radiological investigations to detect hepatitis, would help refine the results. This cross-sectional study cannot be expected to reveal definitive causality. However, it is unique in its findings as it was conducted in a rural agrarian district of a low-middle-income country. The study has produced an essential lead for future evaluation and monitoring.

Table 5 Comparison of means for biochemical parameters by dual therapy combinations_DPP4l study, Anuradhapura 2017

\begin{tabular}{|c|c|c|c|c|c|c|}
\hline \multirow[t]{2}{*}{ Therapy } & \multicolumn{6}{|l|}{ Investigations } \\
\hline & No. of patients & $\mathrm{HbA}_{1 \mathrm{C}}(\%)$ & Pancreatic amylase (U/L) & Serum lipase (U/L) & AST (U/L) & $\mathrm{ALT}(\mathrm{U} / \mathrm{L})$ \\
\hline \multicolumn{7}{|l|}{$\mathrm{OOH}$ group [mean (SD)] } \\
\hline Metformin-glibenclamide & 14 & $9.3(1.4)$ & $36.6(19.2)$ & $42.3(21.4)$ & $21.4(8.2)$ & $21.6(15.2)$ \\
\hline Metformin-gliclazide & 36 & $8.3(1.5)$ & $39.7(15.0)$ & $47.8(16.1)$ & $23.7(10.1)$ & $25.2(17.8)$ \\
\hline Metformin SR-gliclazide & 12 & $8.8(1.8)$ & $35.3(10.5)$ & $48(16.1)$ & $24.8(8.5)$ & $26.5(11.7)$ \\
\hline Metformin-gliclazide MR & 12 & $9.3(2.0)$ & $53.8(30.1)$ & $59.4(21.0)$ & $29.4(10.3)$ & $30(16.4)$ \\
\hline Metformin SR-gliclazide MR & 04 & $9.4(2.8)$ & $187.5(309)$ & $51.5(22.2)$ & $20.5(3)$ & $23.3(5.1)$ \\
\hline Metformin-glimepiride & 31 & $8.9(2.2)$ & $38.2(12.7)$ & $47.6(16.5)$ & $24.7(8.0)$ & $24.9(10.8)$ \\
\hline Metformin SR-glimepiride & 09 & $8.4(2)$ & $33.9(11.9)$ & $50.2(30.6)$ & $48.7(56.9)$ & $36.2(24.1)$ \\
\hline Metformin-tolbutamide & 04 & $8.1(2.8)$ & $42(11.3)$ & $52(4.2)$ & $24.5(3.5)$ & $25(7.1)$ \\
\hline Metformin SR-tolbutamide & 01 & 8.2 & 63 & 52 & 17 & 12 \\
\hline \multicolumn{7}{|l|}{ DPP4I group [mean (SD)] } \\
\hline Sitagliptin-metformin & 04 & $8(1.4)$ & $74.5(36.1)$ & $103.8(54.1)$ & $26.5(6.5)$ & $25(7.2)$ \\
\hline Sitagliptin-gliclazide & 01 & 7.5 & 21 & 49 & 28 & 29 \\
\hline Sitagliptin-gliclazide MR & 01 & 7.9 & 59 & 125 & 23 & 24 \\
\hline Sitagliptin-glimepiride & 01 & 6.2 & 43 & 52 & 12 & 11 \\
\hline
\end{tabular}


Table 6 Comparison of means for biochemical parameters by triple therapy combinations_DPP4I study, Anuradhapura 2017

\begin{tabular}{|c|c|c|c|c|c|c|}
\hline \multirow[t]{2}{*}{ Therapy } & \multicolumn{6}{|l|}{ Investigation } \\
\hline & No. of patients & $\mathrm{HbA}_{1 \mathrm{C}}(\%)$ & Pancreatic amylase (U/L) & Serum lipase $(U / L)$ & AST (U/L) & $\mathrm{ALT}(\mathrm{U} / \mathrm{L})$ \\
\hline \multicolumn{7}{|l|}{$\mathrm{OOH}$ group [mean (SD)] } \\
\hline Metformin-glibenclamide-pioglitazone & 01 & 7.8 & 41 & 46 & 14 & 12 \\
\hline Metformin-glimepiride-pioglitazone & 01 & 7.9 & 80 & 41 & 55 & 43 \\
\hline Metformin SR-tolbutamide-pioglitazone & 01 & 6.8 & 80 & 45 & 27 & 16 \\
\hline \multicolumn{7}{|l|}{ DPP4I group [mean (SD)] } \\
\hline Sitagliptin-metformin-gliclazide & 20 & $9.4(1.6)$ & $43.4(17.8)$ & $58.1(28.2)$ & $27(11.4)$ & $30.7(21.4)$ \\
\hline Sitagliptin-metformin SR-gliclazide & 06 & $9.1(1.9)$ & $36(15.5)$ & $55.8(22.3)$ & $28.7(8.3)$ & $29(12.2)$ \\
\hline Sitagliptin-metformin-gliclazide MR & 05 & $8.6(2)$ & $65.6(35.8)$ & $96.6(55.4)$ & $38.2(26.6)$ & $50.8(40.8)$ \\
\hline Sitagliptin-metformin SR-gliclazide MR & 02 & $8.4(3.3)$ & $44(8.5)$ & $67(35.4)$ & $20.5(12)$ & $32.5(30.4)$ \\
\hline Sitagliptin-metformin-glimepiride & 10 & $8.1(2)$ & $35.7(7.2)$ & $41.5(13.9)$ & $35.9(27.7)$ & $25.6(10.6)$ \\
\hline Sitagliptin-metformin SR-glimepiride & 09 & $7.6(1.1)$ & $57.8(49.4)$ & $109.8(157.7)$ & $24.9(10.3)$ & $29.6(18.9)$ \\
\hline Sitagliptin-metformin-tolbutamide & 02 & $8.1(2.8)$ & $42(11.3)$ & $52(4.2)$ & $24.5(3.5)$ & $25(7.1)$ \\
\hline Vildagliptin-metformin SR-gliclazide & 01 & 8.5 & 36 & 84 & 28 & 34 \\
\hline Vildagliptin-metformin SR-gliclazide MR & 01 & 10.1 & 43 & 57 & 13 & 10 \\
\hline
\end{tabular}

DPP4I dipeptidyl peptidase 4 inhibitors, $M R$ modified release, $\mathrm{OOH}$ other oral hypoglycaemics, SR slow release

\section{Conclusion}

The study showed no significant difference in $\mathrm{HbA}_{1 \mathrm{C}}$, pancreatic amylase, AST and ALT but showed a significantly higher lipase levels among the DPP4I users in comparison to other oral hypoglycaemic drug users. A possibility of dyslipidaemia induced elevation of serum lipase was further discussed.

\section{Additional file}

Additional file 1: DPP4ls and other oral hypoglycemic agents, Anuradhapura, Sri Lanka-2017. This contains the data of the entire study. (XLS $189 \mathrm{~kb})$

\section{Abbreviations}

ALT: Alanine aminotransferase; AST: Aspartate aminotransferase; BMI: Body mass index; CKD-EPI: Chronic kidney disease epidemiology collaboration; DPP4I: Dipeptidyl peptidase 4 inhibitors; eGFR: Estimated glomerular filtration rate; GLP-1: Glucagon-like peptide-1; HbA 1 c: Glycated haemoglobin: MR: Modified release; OOH: Other oral hypoglycaemics;

OPI: Organophosphorus insecticides; SPC: State Pharmaceutical Corporation; SR: Slow release; T2DM: Type 2 diabetes mellitus; USD: United States Dollars

\section{Acknowledgements}

Not applicable.

\section{Funding}

Research grants by Research, Publication \& Higher Degrees Committee, Rajarata University of Sri Lanka (RJT/RP\&HDC/2015/FMAS/R/01, RJT/RP\&HDC/2017/ FMAS/R/01) to DR. The granting agent had no influence on study design, data collection, analysis, and interpretation or on the writing of the manuscript.

\section{Availability of data and materials}

All data generated or analysed during this study are included in this published article (and it's additional files).

\section{Authors' contributions}

DR conceived the idea of the study, and all authors participated in designing the study. DR was involved in data collection and analysis. All authors were involved in data interpretation. DR drafted the manuscript while CJ and SA critically revised it. All authors read and approved the final manuscript.

\section{Ethics approval and consent to participate}

Ethical clearance was obtained from the Ethics Review Committee of Faculty of Medicine and Allied Sciences, Rajarata University of Sri Lanka (ERC/2017/ 07). Institutional permission was obtained from the chairman, State Pharmaceutical Corporation, Sri Lanka. Informed written consent to participate was obtained from all participants.

\section{Consent for publication}

Consent to publish the information provided by the participants was obtained, provided that it will not be possible to identify individual participants in any way.

\section{Competing interests}

The authors declare that they have no competing interests.

\section{Publisher's Note}

Springer Nature remains neutral with regard to jurisdictional claims in published maps and institutional affiliations.

\section{Author details}

'Department of Pharmacology, Faculty of Medicine and Allied Sciences, Rajarata University of Sri Lanka, Saliyapura, Sri Lanka. ${ }^{2}$ Department of Community Medicine, Faculty of Medicine and Allied Sciences, Rajarata University of Sri Lanka, Saliyapura, Sri Lanka.

Received: 13 August 2018 Accepted: 15 January 2019

Published online: 23 January 2019

\section{References}

1. Karuranga S, da Rocha Fernandes J, Huang Y, Malanda B, editors. IDF Diabetes Atlas. 8th ed. Brussels: International Diabetes Federation; 2017.

2. Gifford R, Siribaddana S, Forbes S, Eddleston M. Endocrine-disrupting chemicals and the diabetes epidemic in countries in the WHO South-East Asia region. Lancet Diabetes Endocrinol. 2015;3(12):925-7. 
3. Lasram MM, Dhouib IB, Annabi A, El Fazaa S, Gharbi N. A review on the molecular mechanisms involved in insulin resistance induced by organophosphorus pesticides. Toxicology. 2014;322:1-13.

4. Joshi AKR, Rajini PS. Organophosphorus Insecticides and Glucose Homeostasis. In: Perveen F, editor. Insecticides-pest engineering. InTech; 2012. p. 65-84.

5. Rathish D, Agampodi SB, Jayasumana MACS, Siribaddana SH. From organophosphate poisoning to diabetes mellitus: the incretin effect. Med Hypotheses. 2016;91:53-5.

6. Rathish D, Senavirathna I, Jayasumana C, Agampodi S, Siribaddana S. A low GLP-1 response among patients treated for acute organophosphate and carbamate poisoning: a comparative cross-sectional study from an agrarian region of Sri Lanka. Environ Sci Pollut Res. 2019;26(3):2864-72.

7. Singh AK. Incretin response in Asian type 2 diabetes: are Indians different? Indian J Endocrinol Metab. 2015;19(1):30-8.

8. Kim YG, Hahn S, Oh TJ, Kwak SH, Park KS, Cho YM. Differences in the glucoselowering efficacy of dipeptidyl peptidase-4 inhibitors between Asians and nonAsians: a systematic review and meta-analysis. Diabetologia. 2013;56(4):696-708.

9. Scheen AJ. Pathophysiology of type 2 diabetes. Acta Clin Belg. 2003;58(6): 335-41.

10. Holst JJ. The physiology of glucagon-like peptide 1. Physiol Rev. 2007;225: 1409-39.

11. Nauck MA, Stockmann F, Ebert R, Creutzfeldt W. Reduced incretin effect in type 2 (non-insulin-dependet) diabetes. Diabetologia. 1986;29(1):46-52.

12. Elrick H, Stimmler L, Hlad CJ, Arai Y. Plasma insulin response to oral and intravenous glucose administration. J Clin Endocrinol Metab. 1964;24:1076-82.

13. Perley MJ, Kipnis DM. Plasma insulin responses to oral and intravenous glucose: studies in normal and diabetic sujbjects. J Clin Invest. 1967;46(12):1954-62.

14. Seino Y, Fukushima M, Yabe D. GIP and GLP-1, the two incretin hormones: similarities and differences. J Diabetes Investig. 2010;1(1-2):8-23.

15. Prins JB. Incretin mimetics and enhancers: mechanisms of action. Aust Prescr. 2008;31:102-4.

16. Whalen K. Oral agents. In: Whalen K, Finkel R, Panavelil TA, editors. Lippincott illustrated reviews pharmacology. 6th ed. Philadelphia: Wolters Kluwers; 2015. p. 341-8.

17. Powers AC, D'Alessio D. Insulin secretagogues and oral hypoglycaemic agents. In: Brunton LL, Chabner BA, Knollmann BC, editors. The pharmacological basis of therapeutics. 12th ed. New York: McGray-Hill; 2011. p. 1255-71.

18. Kennedy MSN, Masharani U. Oral antidiabetic agents. In: Katzung BG, Trevor AJ, editors. Basic and clinical pharmacology. 13th ed. New York: McGrawHill; 2015. p. 723.

19. Giorda CB, Sacerdote C, Nada E, Marafetti L, Baldi I, Gnavi R. Incretin-based therapies and acute pancreatitis risk: a systematic review and meta-analysis of observational studies. Endocrine. 2015;48(2):461-71.

20. Wang T, Wang F, Gou Z, Tang H, Li C, Shi L, et al. Using real-world data to evaluate the association of incretin-based therapies with risk of acute pancreatitis: a meta-analysis of 1324515 patients from observational studies. Diabetes Obes Metab. 2015;17(1):32-41.

21. Steinberg WM, Nauck MA, Zinman B, Daniels GH, Bergenstal RM, Mann JFE, et al. LEADER 3--lipase and amylase activity in subjects with type 2 diabetes: baseline data from over 9000 subjects in the LEADER trial. Pancreas. 2014;43(8):1223-31.

22. Giorda CB, Nada E, Tartaglino B, Marafetti L, Gnavi R. A systematic review of acute pancreatitis as an adverse event of type 2 diabetes drugs: from hard facts to a balanced position. Diabetes Obes Metab. 2014;16:1041-7.

23. Lando HM, Alattar M, Dua AP. Elevated amylase and lipase levels in patients using glucagonlike peptide-1 receptor agonists or dipeptidyl-peptidase-4 inhibitors in the outpatient setting. Endocr Pract. 2012;18(4):472-7.

24. Census of Population and Housing, Department of Census and Statistics, Ministry of Finance and Planning, Sri Lanka. 2012.

25. Annual report - 2017 [Internet]. Sri Lanka Labour Force Survey, Department of Census and Statistics, Ministry of Finance and Planning. 2017 [cited 2018 Feb 4]. Available from: http://www.statistics.gov.Ik/samplesurvey/LFS_ Annual\%20Report_2017.pdf.

26. Senarathna L, Jayamanna SF, Kelly PJ, Buckley NA, Dibley MJ, Dawson AH. Changing epidemiologic patterns of deliberate self poisoning in a rural district of Sri Lanka. BMC Public Health. 2012;12(1):593.

27. Rathish D, Agampodi S, Jayasumana C. Acetylcholinesterase inhibitor insecticides related acute poisoning, availability and sales: trends during the post-insecticide-ban period of Anuradhapura. Sri Lanka Environ Health Prev Med. 2018;23(1):27

28. State Pharmaceuticals Corporation of Sri Lanka [Internet]. 2018 [cited 2018 Jan 15]. Available from: http://www.spc.lk/about-spc.php
29. Rathish D, Premarathna I, Jayathilake T, Kandegedara C, Punchihewa K, Ananda $\mathrm{L}$, et al. Availability of essential medicines in selected public, primary and secondary health care institutions of a rural Sri Lankan district: a spot survey. BMC Health Serv Res. 2017;17:11.

30. Rathish D, Bahini S, Sivakumar T, Thiranagama T, Abarajithan T, Wijerathne B, et al. Drug utilization, prescription errors and potential drug-drug interactions: an experience in rural Sri Lanka. BMC Pharmacol Toxicol. 2016;17(1):27.

31. American Diabetes Association. 8. Pharmacologic approaches to glycemic treatment: Standards of Medical Care in Diabetes_-2018. Diabetes Care. 2018;41(Suppl 1):S73-S85.

32. Morisky DE, Green LW, Levine DM. Concurrent and predictive validity of a selfreported measure of medication adherence. Med Care. 1986;24(1):67-74.

33. Adult Tobacco Use Information [Internet]. National Health Interview Survey. 2015 [cited 2017 Mar 10]. Available from: https://www.cdc.gov/nchs/nhis/ tobacco/tobacco_glossary.htm.

34. Drinking Levels Defined [Internet]. National Institute on Alcohol Abuse and Alcoholism. 2016 [cited 2017 Mar 10]. Available from: https://www.niaaa.nih. gov/alcohol-health/overview-alcohol-consumption/moderate-bingedrinking.

35. Jamaluddin $J$, Huri HZ, Vethakkan SR. Clinical and genetic predictors of dipeptidyl peptidase-4 inhibitor treatment response in type 2 diabetes mellitus. Pharmacogenomics. 2016;17(8):867-81.

36. Lyphochek Diabetes Control [Internet]. Bio-Rad. 2018 [cited 2018 Dec 8] Available from: http://www.bio-rad.com/en-Ik/product/lyphochek-diabetescontrol?ID=428c772a-4ee4-4173-a640-a7aef89f9e5c.

37. Precinorm U and Precipath U [Internet]. Roche Diagnostics USA. 2018 [cited 2018 Mar 8]. Available from: https://usdiagnostics.roche.com/ combinedResult.html\#/q/precinorm\%2Bu\%2Band\%2Bprecipath\%2Bu/rt/ docs/s/SCORE_DESC

38. Kim H-S, Shin J-A, Lee S-H, Kim E-S, Cho J-H, Son H-Y, et al. A comparative study of the effects of a dipeptidyl peptidase-IV inhibitor and sulfonylurea on glucose variability in patients with type 2 diabetes with inadequate glycemic control on metformin. Diabetes Technol Ther. 2013;15(10):810-6.

39. Tseng $\mathrm{C}-\mathrm{H}$. Sitagliptin increases acute pancreatitis risk within 2 years of its initiation: a retrospective cohort analysis of the National Health Insurance database in Taiwan. Ann Med. 2015;47(7):561-9.

40. Chang C-H, Lin J-W, Chen S-T, Lai M-S, Chuang L-M, Chang Y-C. Dipeptidy peptidase-4 inhibitor use is not associated with acute pancreatitis in highrisk type 2 diabetic patients. Medicine (Baltimore). 2016;95(7):e2603.

41. Liao K-F, Lin C-L, Lai S-W, Chen W-C. Sitagliptin use and risk of acute pancreatitis in type 2 diabetes mellitus: a population-based case-control study in Taiwan. Eur J Intern Med. 2016;27:76-9.

42. Thomsen RW, Pedersen L, Moller N, Kahlert J, Beck-Nielsen H, Sorensen HT. Incretin-based therapy and risk of acute pancreatitis: a nationwide population-based case-control study. Diabetes Care. 2015;38(6):1089-98.

43. Li L, Shen J, Bala MM, Busse JW, Ebrahim S, Vandvik PO, et al. Incretin treatment and risk of pancreatitis in patients with type 2 diabetes mellitus: systematic review and meta-analysis of randomised and non-randomised studies. BMJ. 2014;348:g2366

44. Ou H-T, Chang K-C, Li C-Y, Wu J-S. Risks of cardiovascular diseases associated with dipeptidyl peptidase-4 inhibitors and other antidiabetic drugs in patients with type 2 diabetes: a nation-wide longitudinal study. Cardiovasc Diabetol. 2016;15(1):41.

45. Duvnjak L, Blaslov K. Dipeptidyl peptidase-4 inhibitors improve arterial stiffness, blood pressure, lipid profile and inflammation parameters in patients with type 2 diabetes mellitus. Diabetol Metab Syndr. 2016;8(1):26.

46. Ni Q, Yun L, Xu R, Shang D. Correlation between blood lipid levels and chronic pancreatitis. Medicine (Baltimore). 2014;93(28):e331

47. Fortson MR, Freedman SN, Webster PD. Clinical assessment of hyperlipidemic pancreatitis. Am J Gastroenterol. 1995;90(12):2134-9.

48. Nawaz H, Koutroumpakis E, Easler J, Slivka A, Whitcomb DC, Singh VP, et al. Elevated serum triglycerides are independently associated with persistent organ failure in acute pancreatitis. Am J Gastroenterol. 2015;1 10(10):1497-503.

49. Wan J, He W, Zhu Y, Zhu Y, Zeng H, Liu P, et al. Stratified analysis and clinical significance of elevated serum triglyceride levels in early acute pancreatitis: a retrospective study. Lipids Health Dis. 2017;16(1):124.

50. Aronson JK, Bankhead C, Mahtani KR, Nunan D. Confounding by indication [Internet]. Catalogue of bias. 2018 [cited 2018 Dec 8]. Available from: https://catalogofbias.org/biases/confounding-by-indication/.

51. Limdi JK. Evaluation of abnormal liver function tests. Postgrad Med J. 2003; 79(932):307-12. 